\title{
Deformation Measurements of Gabion Walls Using Image Based Modeling
}

\author{
Marek Fraštia, Marián Marčiš, Ondrej Trhan \\ Slovak University of Technology, Faculty of Civil Engineering, Radlinského 11, 81368 \\ Bratislava, Slovakia, E-mail: marek.frastia@stuba.sk, marian.marcis@stuba.sk, \\ ondrej.trhan@stuba.sk
}

\begin{abstract}
The image based modeling finds use in applications where it is necessary to reconstruct the 3D surface of the observed object with a high level of detail. Previous experiments show relatively high variability of the results depending on the camera type used, the processing software, or the process evaluation. The authors tested the method of SFM (Structure from Motion) to determine the stability of gabion walls. The results of photogrammetric measurements were compared to precise geodetic point measurements.
\end{abstract}

Key words: image based modeling, deformations of gabion walls, structure from motion.

\section{Introduction}

Image based modeling is very actual technology in this days. Thanks to the high degree of automation in computer vision and SFM ([1], [4], [6]), it is possible to achieve fast and quality results of the imaged objects. There is a great variety of applications for image based modeling using the SFM technology ([2]). It is possible to produce quality models of objects of different dimensions, from few milimeters to tens and hundreds of meters, mostly in fields like archeology, cultural heritage, geology, mining and aerial mapping. But there are always some requirements to meet, if the desired accuracy should be ensured. The most important is the irregular random texture of the object's surface. This requirement is very easy to fulfill in the case of natural stone surfaces like a gabion wall is. The other requirements are related to the camera configuration in relationship to the object. The resulted accuracy of generated 3D surface is around $0.5-2$ pixels ([5]), depending on the type of the surface (higher accuracy on flat surfaces, lower in the presence of sharp details).

\section{Object of measurement}

Gabion wall has been the object of measurement (Figure 1). It is located on the R1 highway in the Lehota crossroad. The left side of the wall is $90 \mathrm{~m}$ long, the supporting concrete wall of the bridge is $37 \mathrm{~m}$ long and the right side of the gabion wall is $85 \mathrm{~m}$ long. The wall is $7.4 \mathrm{~m}$ high in the left side and 5.8 high in the right side. The whole building construction has arc shape.

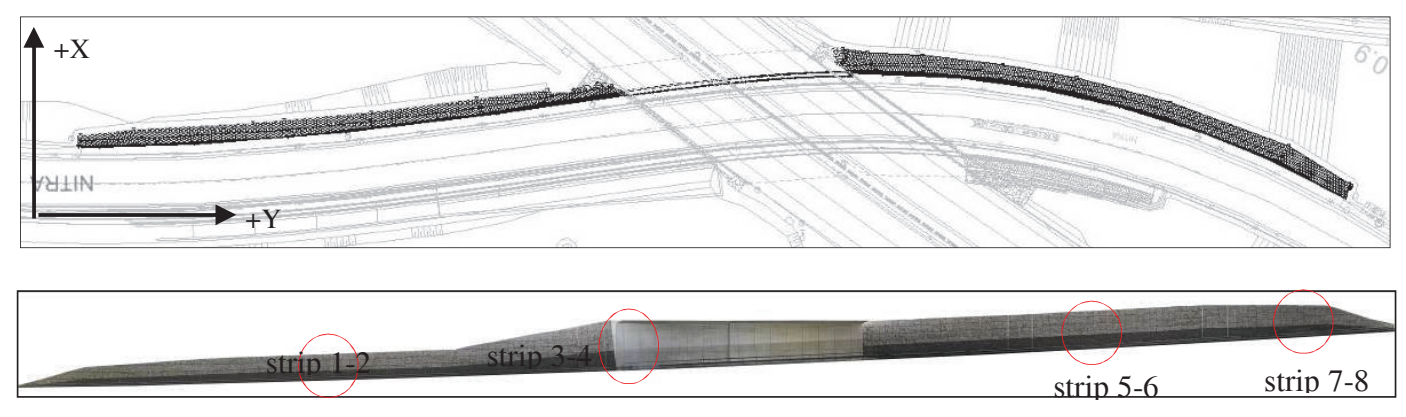

Figure 1: The ground plan (up) and the front view (down) of the observed gabion wall 
There are changes in high and position of 10-100 mm assumed created by the influence of the subsidence of the building structure and the weather conditions. Quarterly intervals of surveying were proposed with the $3 \mathrm{~mm}$ required accuracy of the height and position of the observed points. The observed points were set in 4 pairs of steel strips (Figure 1) firmly fixed in the wall and signalized by reflective foils (Figure 2) for precise measurement of the distances.

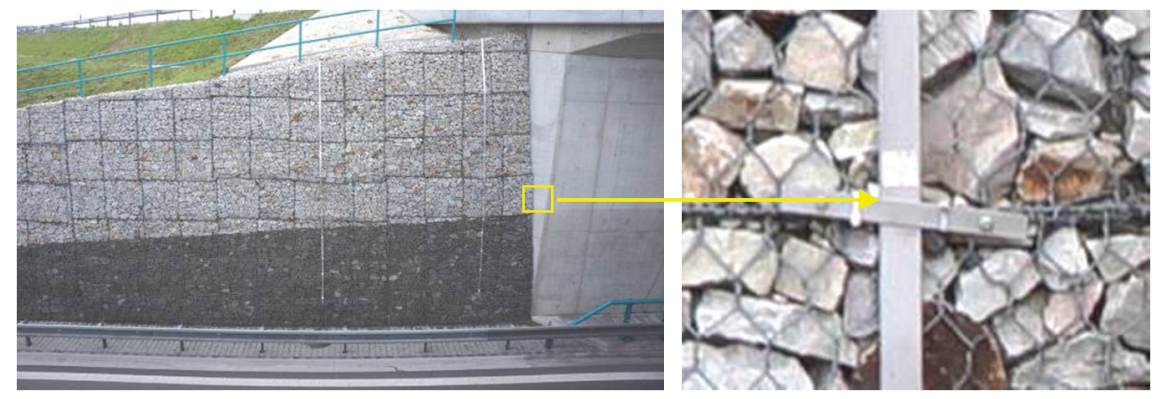

Figure 2: The observed points (right) and the pairs of steel strips (left)

We proposed to expand the mentioned geodetic point measurement with the unselective area measurement using the technology of image based modeling. The results of such measurement are likely to the technology of terrestrial laser scanning - point cloud with high geometrical resolution, which documents not only the position of the selected points but also the whole surface of the observed object. The purpose of this method is to document the changes specifically in the direction perpendicular to the wall (in $\mathrm{X}$ axis direction).

\section{The methodology of measurement and the used equipment}

Geodetic measurements of observed and reference points was realized by the spatial polar method using instrument the Leica TS30 (total station) with following accuracy characteristics: the mean error of angular measurement $0.5^{\prime \prime}$ and of distance measurement on the reflective foils $1 \mathrm{~mm}+$ $1 \mathrm{ppm}$. The reference network is created by 12 points signalized with the reflective foils and installed on the surrounding objects (lamps, bridges, crash barriers, wells and portals). The coordinates and the heights were determined in a local geodetic network with mean errors smaller than $m_{Y X} \leq 2 \mathrm{~mm}, m_{H} \leq 2 \mathrm{~mm}$. The stability of the network points is checked in every epoch of the measurement. Every pair of the strips of the observed points is measured from separate free standpoint to ensure that the direction of measurement is as perpendicular as possible to the reflective foil and to achieve the highest possible accuracy of the measured distance. The mean errors of observed points in the position and height do not exceed $m_{Y X}=3 \mathrm{~mm}, m_{H}=3 \mathrm{~mm}$. Overall there is 85 observed points (about 10 on each strip).

The photogrammetric methods allowed not only the measurement of observed points but also the complete surface scanning of the whole object. Some of observed points were selected as control points $(\mathrm{CP})$, the remaining points served as check points $(\mathrm{ChP})$ since their coordinates are known from the geodetic measurement. There were 2 cameras used for taking the images: the $33 \mathrm{MP}$ middle format digital back LEAF APTUS II-7 and the 24 MP high end compact SONY NEX-7 with interchangeable lenses (Tab. 1).

Imagery was realized from the distance of 11 meters from the opposite side of the road (from the ground level) and the left side of the wall was photographed additionally from the top level of the opposite wall (Figure 3). After all the images of the left side of the wall created 2 image strips, the concrete wall and the right side of gabion wall are displayed only on 1 strip. In one epoch there were together 100 images with the PhaseOne camera and 91 images with SONY camera taken. The longitudinal image overlap was about $70 \%$, transverse $100 \%$, base to distance ratio about $0.27(1: 3.7)$. 
Table 1: Technical specifications of used cameras

\begin{tabular}{|l|l|l|l|}
\hline PhaseOne 645 (body) - LEAF Aptus II-7 (digital back) \\
\hline Number of pixels & 33000000 & Data format & JPEG \\
\hline Size of the CCD sensor & $(36 \times 48) \mathrm{mm}^{2}$ & Image scale & $1: 245\left(\mathrm{GSD}^{1}=1.7 \mathrm{~mm}\right)$ \\
\hline Size of one pixel & $7.02 \mu \mathrm{m}$ & Lenses & PhaseOne F2.8 \\
\hline Resolution & $6666 \times 4992$ & Focal length & $\mathrm{f}=45 \mathrm{~mm}$ \\
\hline SONY NEX-7 & \multicolumn{3}{|l|}{} \\
\hline Number of pixels & 24000000 & Data format & JPEG \\
\hline Size of the CCD sensor & $(24 \times 16) \mathrm{mm}^{2}$ & Image scale & $1: 550\left(\mathrm{GSD}^{1}=2.3 \mathrm{~mm}\right)$ \\
\hline Size of one pixel & $4.2 \mu \mathrm{m}$ & Lenses & E F2.8 \\
\hline Resolution & $6000 \times 4000$ & Focal length & $\mathrm{f}=20 \mathrm{~mm}$ \\
\hline
\end{tabular}

${ }^{1}$ GSD - Ground Sample Distance is the size of pixel on the object`s surface

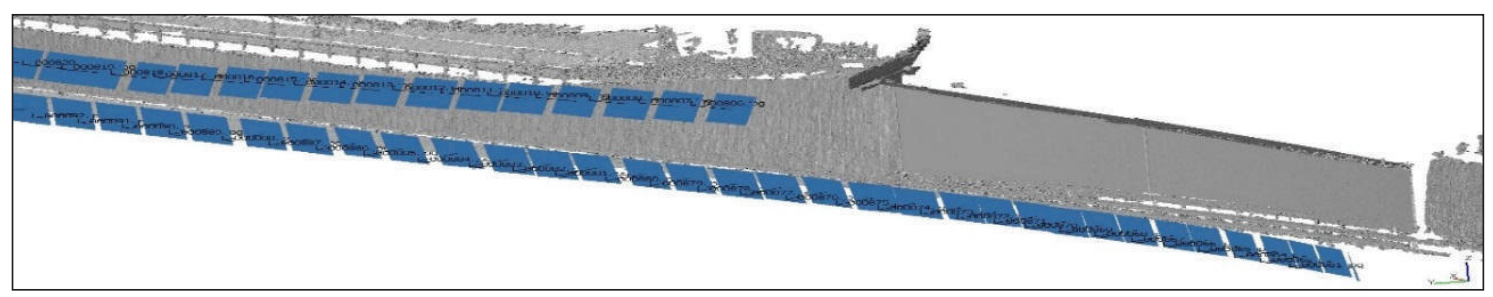

Figure 3: Taking of the images in 2 strips

\section{Results of the measurements}

The results of geodetic measurements by the total station between epochs $0(14 / 10 / 2013)$ and 1 $(12 / 12 / 2013)$ realized by company GEOsys s.r.o. indicate the stability of the left side of the gabion wall and the concrete bridge and the displacements of the observed points stabilized in the right side of the gabion wall up to $7 \mathrm{~mm}$ in the direction to the road. These values are yet not reliably proving the displacement. The height changes are minimal in values of $\pm 2 \mathrm{~mm}$.

The measurement of observed points for the purpose of photogrammetric processing wasn't able to synchronize with above mentioned geodetic measurements, therefore it is not possible to correlate them. Our epochs were realized on the 23/11/2013 and 22/01/2014. The statistic of differences (Tab. 2) on individual pairs of strips implies small changes in individual axes, under the border of detectability of displacements. In terms of the changes of the surface the values of changes in $\mathrm{X}$ direction are substantial for us, i.e. the changes in the direction perpendicular to the wall. The highest changes occurred on the 5-6 and 7-8 strips, in the right side of the gabion wall in the direction to the road.

Photogrammetric processing has been realized in the system Agisoft PhotoScan Professional, which can generate very detailed georeferenced 3D digital models and orthophotomosaics with high degree of automation ([7]). After the automatic orientation of the images including camera calibration there is necessary to manually measure the CPs (if the coded targets are not available). Any distortions of the model are caused by the various systematic effects (e.g. lens distortion), which the images contains, and by the number of used images. The more images in the strip used and larger deviations are from exact central projection of images, the larger deformations resulted model will content. These deformations are effectively eliminated by the properly chosen number and localization of CPs. By increasing the number of CPs we increase the geometric quality of the model on the one hand, but time and cost will rise on the other hand. For the purpose of evaluating the quality of the model, we tested the deviations for each geodetically measured point 
(check point) by choosing the different ways of fitting for both cameras. Scheme of the CPs layout illustrates Figure 4.

Table 2: The statistic of the coordinate differences between the 23/11/2013 and 22/01/2014 epochs.

\begin{tabular}{|c|c|c|c|c|}
\hline & Displacements [mm] & Y & X & Z \\
\hline \multirow{3}{*}{$\begin{array}{c}\text { Strip 1-2 } \\
16 \text { points }\end{array}$} & Max. & 1.0 & 1.7 & 1.6 \\
\cline { 2 - 5 } & Min. & 0.0 & 1.1 & 0.7 \\
\cline { 2 - 5 } & Arithmetical average & $\mathbf{0 . 4}$ & $\mathbf{1 . 4}$ & $\mathbf{1 . 2}$ \\
\hline \multirow{2}{*}{$\begin{array}{c}\text { Strip 3-4 } \\
25 \text { points }\end{array}$} & Max. & 0.8 & -0.1 & 2.1 \\
\cline { 2 - 5 } & Min. & 0.0 & -1.3 & 1.1 \\
\cline { 2 - 5 } Strip 5-6 & Arithmetical average & $\mathbf{0 . 2}$ & $\mathbf{- 0 . 5}$ & $\mathbf{1 . 6}$ \\
\cline { 2 - 5 } 22 points & Max. & 2.4 & -1.0 & 0.1 \\
\cline { 2 - 5 } & Min. & 0.0 & -3.7 & -2.2 \\
\hline \multirow{2}{*}{ Strip 7-8 } & Arithmetical average & $\mathbf{0 . 7}$ & $\mathbf{- 2 . 6}$ & $\mathbf{- 0 . 8}$ \\
\cline { 2 - 5 } 22 points & Max. & 1.4 & -1.0 & 2.1 \\
\cline { 2 - 5 } & Min. & -0.4 & -2.7 & 0.5 \\
\cline { 2 - 5 } & Arithmetical average & $\mathbf{0 . 5}$ & $\mathbf{- 1 . 9}$ & $\mathbf{1 . 4}$ \\
\hline
\end{tabular}

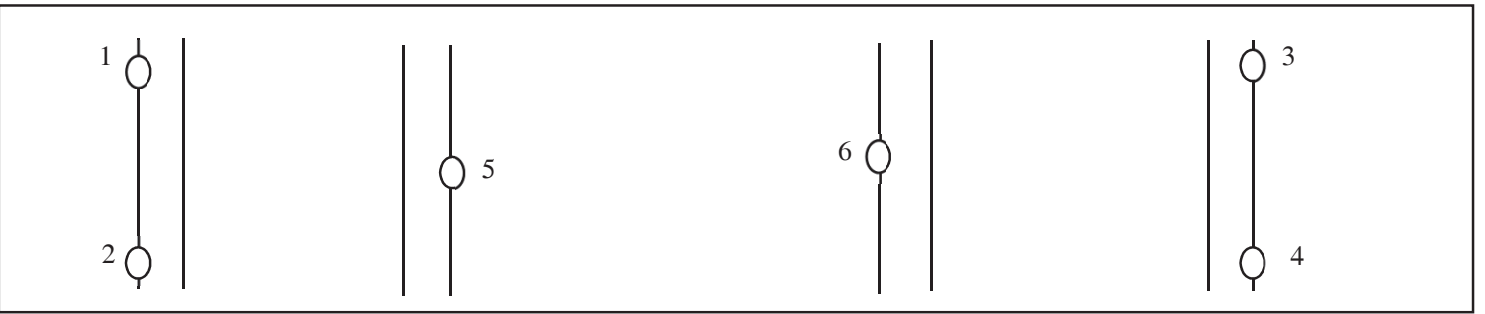

Figure 4: Scheme of layout of control points
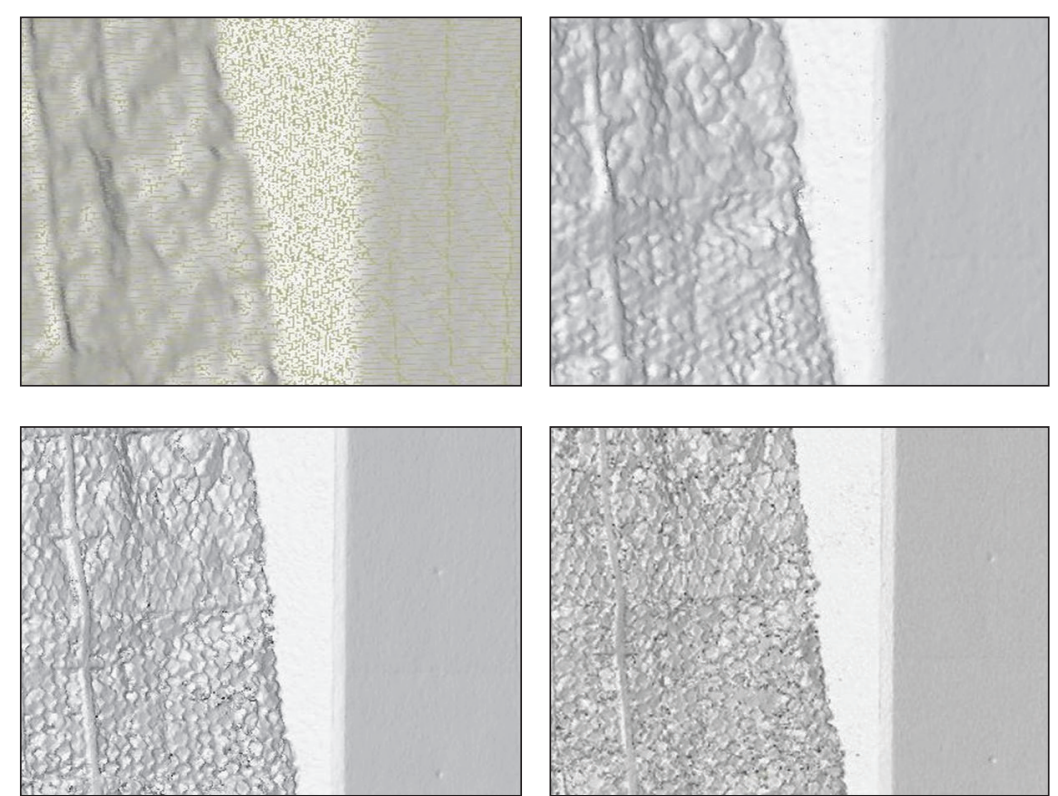

Figure 5: Level of detail of cloud of points shown as shaded cloud of points, detail from left: low, medium, high, ultra high (down) 
Table 3: Differences between geodetic and photogrammetric coordinates

\begin{tabular}{|c|c|c|c|c|c|}
\hline \multirow{2}{*}{$\begin{array}{l}\text { Camera } \\
\text { Nb. of } \\
\text { strips }\end{array}$} & & \multicolumn{4}{|c|}{ Differences between geodetic and photogrammetric coordinates } \\
\hline & & & $\mathbf{Y}[\mathbf{m m}]$ & $\mathbf{X}[\mathbf{m m}]$ & $\mathbf{Z}[\mathbf{m m}]$ \\
\hline \multirow{3}{*}{$\begin{array}{c}\text { PHASE } \\
\text { ONE } \\
1 \text { strip }\end{array}$} & \multirow{3}{*}{$\begin{array}{c}4 \mathbf{C P} \\
81 \mathrm{ChP}^{1}\end{array}$} & Max & 2.5 & 0.4 & 0.6 \\
\hline & & Min & -33.8 & -226.0 & $-20,3$ \\
\hline & & Quadratic mean & 17.2 & 147.9 & 13.2 \\
\hline \multirow{9}{*}{$\begin{array}{c}\text { PHASE } \\
\text { ONE } \\
2 \text { strips }\end{array}$} & \multirow{3}{*}{$\begin{array}{c}4 \mathbf{C P} \\
81 \mathrm{ChP}^{1}\end{array}$} & Max & 1.2 & 9.3 & 0.5 \\
\hline & & Min & -8.8 & -2.6 & -3.7 \\
\hline & & Quadratic mean & 4.8 & 3.9 & 1.9 \\
\hline & \multirow{3}{*}{$\begin{array}{c}5 \text { CP } \\
80 \mathrm{ChP}^{1}\end{array}$} & Max & 1.8 & 6.7 & 1.1 \\
\hline & & Min & -2.4 & -3.1 & -3.1 \\
\hline & & Quadratic mean & 0.9 & 2.5 & 1.0 \\
\hline & \multirow{3}{*}{$\begin{array}{c}\mathbf{6} \mathbf{~ C P} \\
79 \mathrm{ChP}^{1}\end{array}$} & Max & 1.7 & 2.7 & 1.6 \\
\hline & & Min & -2.4 & -3.0 & -2.2 \\
\hline & & Quadratic mean & 0.8 & 1.1 & 0.7 \\
\hline \multirow{9}{*}{$\begin{array}{l}\text { SONY } \\
\text { NEX-7 } \\
2 \text { strips }\end{array}$} & \multirow{3}{*}{$\begin{array}{c}4 \mathbf{C P} \\
81 \mathrm{ChP}^{1}\end{array}$} & Max & 3.1 & 2.3 & 3.1 \\
\hline & & Min & -10.7 & -13.0 & -2.8 \\
\hline & & Quadratic mean & 5.0 & 5.3 & 1.5 \\
\hline & \multirow{3}{*}{$\begin{array}{c}5 \text { CP } \\
80 \mathrm{ChP}^{1}\end{array}$} & Max & 7.6 & 5.3 & 1.0 \\
\hline & & Min & -1.2 & -4.6 & -3.8 \\
\hline & & Quadratic mean & 3.2 & 2.3 & 1.4 \\
\hline & \multirow{3}{*}{$\begin{array}{c}\mathbf{6 ~ C P} \\
79 \mathrm{ChP}^{1}\end{array}$} & Max & 1.9 & 3.0 & 1.7 \\
\hline & & Min & -1.9 & -4.6 & -1.9 \\
\hline & & Quadratic mean & 0.9 & 1.8 & 0.7 \\
\hline
\end{tabular}

${ }^{1}$ number of check points, from which is computed a statistics

The above table can be summarized in the following conclusions and recommendations:

i. Inappropriate imagery and processing data can lead to a deformation of the model up to 2 decimal places worse than can be achieved. These deformations may be undetected in the standard visual and statistic controls.

ii. If it is possible, we should take images in 2 (or more) parallel strips.

iii. Choose a lens with smaller distortion.

iv. Choose a pair of CPs one above the other in horizontal intervals of every 10 images.

v. Use some pairs as check points in the processing.

vi. Set accuracy of CPs as fixed if we don't have doubts about their high quality of determination.

vii. Finely adjust the weights for the tie points sensitive (case by case) according to deviations on the control points.

viii. For the generation of the surface points, we can use the check points as the control points and fix them $\left(m_{X Y Z}=0\right)$.

With the compliance of these principles it is realistic to achieve the accuracy of the point cloud 2 pixels in the photographing direction, i.e. perpendicular to the object. In our case it is $3.4 \mathrm{~mm}$ (PhaseOne camera), respectively $4.6 \mathrm{~mm}$ (Sony camera). In the parallel plane with the image plane, i.e. in the plane of the wall the real accuracy of the model is about 1 pixel (1.7 respectively $2.3 \mathrm{~mm})([3])$.

The level of detail (Figure 5) can be chosen within the meaning of 1 point on 1 pixel or in lower resolution, i.e. 1 point on every 2 pixels, 1 point on every 4 pixels etc. The number of points and 
the detail of the surface (the distance between adjacent points) at various settings for camera Phase One are documented in Tab. 4:

Table 4: Impact of the level of the processing on the number of points and the density of point cloud of whole wall (100 images)

\begin{tabular}{|c|c|c|c|c|c|}
\hline $\begin{array}{c}\text { Level of processing } \\
\text { (process pixel - every) }\end{array}$ & $\begin{array}{c}\text { ultra high } \\
1 .\end{array}$ & $\begin{array}{c}\text { high } \\
2 .\end{array}$ & $\begin{array}{c}\text { medium } \\
4 .\end{array}$ & $\begin{array}{c}\text { low } \\
8\end{array}$ & $\begin{array}{c}\text { lowest } \\
16 .\end{array}$ \\
\hline step GSD [mm] & 1.7 & 3.4 & 7 & 14 & 28 \\
\hline number of points/m & 444000 & 111000 & 20400 & 5100 & 1200 \\
\hline $\begin{array}{c}\text { total number of points } \\
{\left[\mathrm{x} 10^{6}\right]}\end{array}$ & 288 & 72 & 18 & 4.5 & 1.1 \\
\hline
\end{tabular}

The result of the epoch comparison of the wall surfaces in the X-axis (direction approximately perpendicular to the wall) is a colored differential map (Figure 6). Compared were these epochs: 23/11/2013 - 22/01/2014, both from images from camera Phase One. From Figure 6 we can see, that differences between epochs in left part, on concrete wall and on a part of right wall are in an interval of $\pm 3 \mathrm{~mm}$, thus in measurement accuracy. For about $2 / 3$ of the right part of the gabion wall are the differences represented by values of up to $+9 \mathrm{~mm}$, where the sign "+" in this instance is the direction of displacement to the road. Even this value doesn't represent a demonstrable displacement, because with the precision of the determination of the surface in a direction perpendicular to the surface of $3.4 \mathrm{~mm}$ we reliably detect a change in this direction with a probability of $95 \%$ for values above $12 \mathrm{~mm}$.

At lower processing resolution, the problem can be in making of 3D model due to wires of gabion mesh. The mesh is more or less in front of stones and that fact caused lower accuracy of model surface. On the other hand, the higher resolution, the more points is generated and more hardware problems can occur.

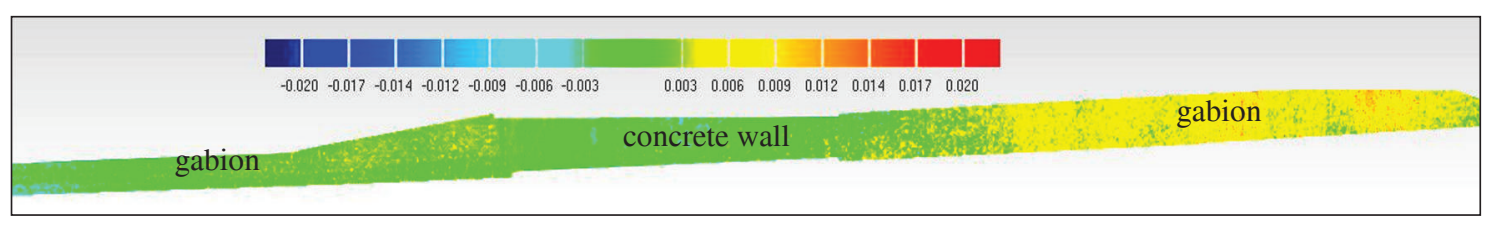

Figure 6: Difference map between epochs 23/11/2013 - 22/01/2014, Green: \pm 3 mm, yellow: +(39) $\mathrm{mm}$

\section{Conclusion}

This contribution was aimed to show the possibilities of photogrammetric documentation of the gabion walls for the purposes of creation of detailed 3D models and the measurements of displacements. The main advantages are the simplicity of the data acquisition, surface documentation of object and the sufficient accuracy of the results. On the other hand, the big sensitivity of the results to the method of field data collection and the data processing requires adequate knowledge and experience of human operator, which guarantee the quality of the results.

\section{Acknowledgements}

The authors of the article thank to GEOsys s.r.o. for the offer of partnership in this project as well as for the provided technical information, documents and assistance in solving the project.

The paper is solved within the project VEGA no. 1/0133/14. 


\section{References}

[1] CIPOLLA, R.: Structure from motion. [online] 2008. [cited 10.10.2012]. Available from $<$ http://mi.eng.cam.ac.uk/ cipolla/publications/contributionToEditedBook/2008-SFMchapters.pdf>

[2] DONEUS, M., VERHOEVEN, G., FERA, M., BRIESE, CH., KUCERA, M., NEUBAUER, W.: From deposit to point cloud: a study of low-cost computer vision approaches for the straightforward documentation of archaeological excavations. GEOINFORMATICS (Faculty of civil engineering, Czech Technical University in Prague). 2011, 6. pp.81-88, ISBN 978-80-010-4885-6.

[3] FRAŠTIA, M.: Laser versus image scanning of stone massifs. Mineralia Slovaca. - ISSN 0369-2086. - Vol. 44, No. 2 (2012), s. 177-184

[4] JUNGHAUS, O.: Studies on the photogrammetric acquisition of point clouds with the PhotoModeler Scanner system, bachelor thesis, Bochum University of Applied Sciences, 2010, [online]. [cited 22.02.2013] Available from <http://www.hochschulebochum.de/fileadmin/media/fb_v/labore/photogrammetrie/Absolventen/Bachelorarbeit_ Oliver_Junghans.pdf>

[5] MARČIŠ, M.: Protection and restoration of cultural heritage using the methods of digital photogrammetry, PhD thesis, Slovak University of Technology, Faculty of Civil Engineering, Department of Surveying, 2013.

[6] PAVELKA, K., ǨEZNíČEK, J.: New Low-cost Automated Processing of Digital Photos for Documenation and Visualisation of the Cultural Heritage. Geoinformatics [online]. 2011, vol. 6, no. 6, p. 245-258. Available from <http://www.geoinformatics.fsv.cvut.cz>. ISSN 1802-2669.

[7] SEMYONOV, D. Algorithms Used in Photoscan, Agisoft PhotoScan Forum, 03.05.2011 [cited 03.10.2012] <www.agisoft.ru/forum/> 